\title{
Collaboration for Community-Based Cultural Sustainability in Island Tourism Development: A Case in Korea
}

\author{
Xiubai Li ${ }^{1}$, Jinok Susanna Kim ${ }^{2, *}$ and Timothy J. Lee ${ }^{3}$ \\ 1 School of History, Culture and Tourism, Guangxi Normal University, Guilin 541001, China; \\ lixiubai@gxnu.edu.cn \\ 2 Department of Airline Service, Sehan University, Dangjin 31746, Korea \\ 3 Faculty of Hospitality and Tourism Management, Macau University of Science and Technology, \\ Macao, China; tjlee@must.edu.mo or timothylee728@gmail.com \\ * Correspondence: s2924@sehan.ac.kr; Tel.: +82-41-359-6028
}

check for updates

Citation: Li, X.; Kim, J.S.; Lee, T.J. Collaboration for Community-Based Cultural Sustainability in Island Tourism Development: A Case in Korea. Sustainability 2021, 13, 7306. https://doi.org/10.3390/su13137306

Academic Editor:

Diego A. Barrado-Timón

Received: 14 June 2021

Accepted: 28 June 2021

Published: 30 June 2021

Publisher's Note: MDPI stays neutral with regard to jurisdictional claims in published maps and institutional affiliations.

Copyright: (c) 2021 by the authors. Licensee MDPI, Basel, Switzerland. This article is an open access article distributed under the terms and conditions of the Creative Commons Attribution (CC BY) license (https:/ / creativecommons.org/licenses/by/ $4.0 /)$.

\begin{abstract}
Constructive collaboration with host communities while maintaining their traditional culture is crucial when planning tourism ventures, particularly if ensuring sustainability is considered important. This paper investigates the cultural sustainability of Jeju Island in South Korea and whether collaboration with community-based tourism ensures this sustainability through in-depth interviews with local residents. The first part of the interview focuses on cultural components to assess the current situation of cultural sustainability on the island, and the second part is related to that collaboration. The findings of the interviews indicate that: (i) there are certain negative indications of cultural sustainability in that Jeju people holding informal power became vulnerable in the face of tourism demand; (ii) several barriers exist in the facilitation of community-based tourism collaboration notwithstanding the beneficial trends, and (iii) there is a strong relationship between collaboration and cultural sustainability. It is also noted that the collaboration itself does not coincide with the actualization of cultural sustainability so long as current power disparities exist. The study delivers significant implications to the tourism policymakers and practitioners on how sustainable tourism development should be planned and operated to secure a long-term benefit especially focused on how the local community should be involved in the overall development process.
\end{abstract}

Keywords: collaboration; cultural sustainability; community-based tourism; sustainable tourism development; local residents' participation

\section{Introduction}

The world is changing and experiencing shifts in social values, influencing the way people behave as individuals, businesses, and governments [1]. Part of the change comes from an increasing recognition that the pursuit of economic growth has had serious negative impacts on natural and socio-cultural environments [2]. Issues such as climate change, depletion of the ozone layer, unequal income distribution, and the exhaustion of resources are now recognized [3]. These negative aspects have led to calls for sustainable development [4]. Tourism is one of the industries that should engage in sustainable development given its magnitude, rate of expansion, and ability to have serious adverse impacts on the environment [5].

Sustainable tourism is often discussed in terms of a balance between socio-economic and environmental concerns, and this is especially the case if tourism utilizes the environment as a resource [6]. However, to achieve sustainable tourism that is culturally acceptable, economically viable, and socially compatible, there needs to be a long-term commitment that offers flexible policies while moving toward its successful implementation [7]. That the economic and social activities tend to be concentrated in the interconnectivity between economic, environmental, social, cultural, and political spheres is pervasive, making sustainable tourism development essential rather than an option $[8,9]$. 
Clarke [10] presented some insights into the concept of sustainable tourism based purely on a literature review of past developments. Essentially, the goal of sustainability means that there needs to be an understanding of the general progress of a community [11]. This includes the previous condition(s), the current discourse, and their interpretations and adaptions, as this will give a well-defined comprehension of the need to address future developments that move towards the ultimate goal of sustainability [4]. In addressing the longstanding problems of the tourism industry, Holtorf [12] argues that the focus of sustainability is likely to be on repairing the damage done by previous development initiatives.

Among significant sustainable development and sustainable tourism discourse, the concepts of sustainable development largely tend to frame the perspective on the central environment-economic relationship [13]. The cultural dimension has had little or no focus in the debate of sustainable development, although the cultural attraction in the community is one of the most competitive and powerful tools and resources for sustainable tourism development [2]. Tourism collaboration with host communities and their culture is meaningful for preserving the cultural subjectivity of local people as well as promoting sustainable tourism that needs private effect [14]. This study concentrates on cultural sustainability as an important aspect of sustainable development [15].

Jeju Island in South Korea, where there is strong intimacy between the environment and culture, is undergoing large changes from the tourism influx, and it is likely that these changes will significantly affect local people's culture and dignity [16]. Hence, we need to examine cultural sustainability on the island and how community-based tourism collaboration is associated with that sustainability [17]. This study examines residents' views to assess cultural sustainability on Jeju Island and investigates communitybased collaboration as an important mechanism for sustainability [14]. The objectives of the current study are to examine: (a) how the local community perceives the cultural impacts of tourism; (b) whether cultural sustainability is associated with community-based collaboration, and (c) what the prospects are for community-based tourism collaboration.

\section{Literature Review}

\subsection{Stakeholders and Socio-Cultural Impact in Tourism Development}

Tourism development, especially in many Asian countries, is commonly initiated, managed, and completed by central government agencies. Public authorities often maintain highly bureaucratic attitudes towards the private sector with their administrative power [4]. They are the dominant forces among the different stakeholders that create a vertical relation between the stakeholders. However, the power situation of the public sector easily fluctuates according to the political trends 'within' the government agencies [14] Public staff members are more sensitive to protecting their positions inside their agencies than their relationships with other private stakeholders.

The attitude of conflict and collaboration between the stakeholders is often linked to the political situations of the central government [3]. This causes continuous negative phenomena in the relationship between the stakeholders, especially local residents, such as: (a) a lack of policy consistency, (b) distrust among the stakeholders, (c) weak interest and participation of private sectors, (d) a lack of a 'sharing of vision' between the participants, and (e) a lack of sharing public interest [14].

Private stakeholders often complain that the government agency unilaterally plans tourism development without consideration of the private sectors' viewpoints. Meanwhile, the central government feels perturbed because it believes that the private stakeholders are demanding, egotistical, and stubborn. However, not much healthy effort is made to listen to everyone to seek understanding, compromise, or collaboration [1]. The cross-sectoral collaboration between stakeholders for social problem-solving has received attention. The socio-cultural impacts of tourism development are significant since they may have a more substantial influence on the community [17]. However, they have been commonly evaluated as a one-dimensional concept [5]. One possible reason is that socio-psychological attitudes and impacts are correlated and hard to separate completely [14]. Moreover, 
tourism social impacts affect not only local society in negative ways but also in positive ways. Sustainable tourism requires that the positive impacts of tourism are enhanced, while the adverse consequences on development are reduced [17].

\subsection{Cultural Sustainability}

Sustainable development (SD) and sustainable tourism (ST) might not be driven by the recognition of 'intrinsic' values. It is humanity and the human environment relationship that means SD has a cultural component [18,19]. Culture shapes a person's view of the environment, and the natural environment is culturally constructed by 'intimate interdependencies' [15]. Hence, environmental disturbance by tourism is frequently linked to cultural intrusions, particularly in societies where there is a close relationship between the physical environment and cultural values [20]. International tourism has a significant role in cultural exchange, allowing importation and exportation of diverse cultural constructs. Cultural exchange is a benefit of the tourism industry; true authenticity comes from a community's identity. Sustainable tourism must embrace the cultural context [17]. Wearing and McDonald [21] believe that when communities pay as much attention to the conceptualization of tourism as tourists, tourism can go beyond economic profit and consider better experiences and authentic presentation. However, this does not mean eliminating economics but integrating it and being aware of the complete interdependence of many aspects in tourism.

The cultural aspect has gained little attention in the debate on sustainability, maybe because the impacts on society are slow, difficult to determine [22,23], and current social paradigms are not prepared for the transfer of power [24]. Cultural issues deal with peoples identities, belonging, spiritual meaning, and moral and legal rights. Thus, the consideration of culture in the context of sustainable development is closely related to indigenous communities as the most vulnerable and is likely to be disregarded [25]. The main reasons why contemporary sustainable tourism pays little attention to cultural aspects could be: (a) cultural aspects are problematic to measure [22]; (b) culture is viewed as another substitutable commodity [20]; and (c) cultural aspects cannot be expressed in a political manner [14].

\subsection{Collaboration for Cultural Sustainability}

Collaboration is recognized as essential to progress toward sustainable development and sustainable tourism. The nature and extent of collaboration are influenced by environmental and economic matters [26]. Although collaboration is seen as vital, the extent of collaboration in the quest for sustainable tourism remains narrow in terms of perspectives and practices [27]. Collaboration has tended to focus on local community consent for tourism management by inviting greater involvement [28]. Researchers contend that community involvement in establishing desirable conditions is perhaps the single most important element of sustainable development in tourism [21,29]. In the understanding of the significance of the cultural aspects of sustainable development, the dignity of human beings is crucial. Therefore, it becomes pertinent to examine how community-based collaboration is associated with the cultural dimensions of sustainability: quality of life related to cultural identity, cultural integration, and cultural rights [6]. Mowforth and Munt [22] argue that cultural sustainability refers to the ability of people to retain or adapt those elements of their culture that distinguish them from other cultures.

Cultural impacts from even a small influx of visitors are inevitable, and 'control' of any that are harmful influences, stress on the responsive behavior of the visitors, and the prevention of damage to local culture is essential to the sustainability of tourism [30]. Cultural adoption occurs through transculturation, the way in which marginalized or subordinated groups select from material transmitted to them by dominant metropolitan cultures [18]. Sometimes this results in changes towards the wishes of the dominant culture [22]. Hence, communities impacted by tourism have the right to be engaged to moderate those impacts and maintain their own community cultures [31]. In this way, 
community-based collaboration can be considered to advance this cultural right and realize cultural democracy since it is an autonomous action where individuals encounter the opportunities and responsibilities of citizenship [14].

Opportunities for such collaboration include working together for mutual benefit, joining in the process of self-sufficiency, and responding to authoritative decisions affecting community culture or personal life [17]. Therefore, it might be an educational and empowering process where residents, in partnership with those able to assist them, identify needs and gradually become conscious of the responsibility to manage themselves, and control and appraise collaborative decision making and actions [31]. In this sense, communitybased collaboration ideally engages a distribution of power, from those who have had major decision-making roles to those who historically have not had such a role [14]. Community participation can be a tool to achieve a balance of power and assert local community views over those of the developers or local authorities.

Additionally, it may determine successful collaboration and prevent manipulation of communities in the collaborative process $[29,32]$. The field of community development has long considered that at the heart of collaboration is self-governance and local control over change, making the process itself more significant than the result $[17,18]$. This highlights that community-based collaboration is needed to actualize a 'sustainable community'. In this case, tourism is interpreted as a vehicle to contribute to the sustainable development process, which is a prerequisite of true ST. Hence, collaboration is associated with the 'how' of tourism (mechanism of practice for cultural sustainability), rather than the 'why' (the role of tourism or ST principles) [23].

Low [33] emphasized the concept of community-based collaboration as a powerful instrument to educate local people in their rights, laws, and good political sense. Since the leadership of society would inevitably be in the hands of the elite, it is necessary to ensure that its members are educated in the broadest sense and deeply value individual liberty and democracy [1]. The individual would, therefore, learn the politics of democracy by participating in local institutions and associations [14]. Based on Low's argument, without collaboration, democracy and individual liberty may not be sustainable. Hence, to embrace sustainable cultural tourism in depth, collaboration is not only a useful mechanism for problem-solving; it is also a legitimate and crucial policy goal of sustainable development [23].

In the real world, however, marketers, whose main desire is profit, are not likely to accept pure 'educational processes' for communities, sacrificing time and cost [34]. The existence of unbalanced power and resource flows prevents the facilitation of community-based collaboration [21,26]. Miller and Twining-Ward [35] explain that involvement, which makes community-based collaboration happen, is a battle between the 'principle' of having everyone involved and the 'pragmatism' of getting the group to agree. Hence, there are inadequate bases for the development of this theoretical approach without activating the basic and fundamental components of the initiation and effectiveness of collaboration.

\subsection{Barriers to Community-Based Collaboration}

The critical factors of facilitation and effective collaboration seem to be able to be converted into constraining factors in cases where there is no favorable condition for collaboration [13]. Thus, constraining factors to successful partnerships can be found by discussing the negative side of each success factor previously identified [36]. Nevertheless, since community-based collaboration confronts more challenges than any other form of collaboration, these will be dealt with in more detail along with any hindering factors identified regardless of the success factors. Tosun [32] tried to identify barriers to community participation and classified those limitations into three groups: constraints at the operational, structural, and cultural levels (Table 1). His study focused on developing countries or peripheral destinations in developed countries and demonstrated that hindrances to collaboration exist to a different extent (and contents) across cultures. 
Table 1. Barriers to community participation in tourism.

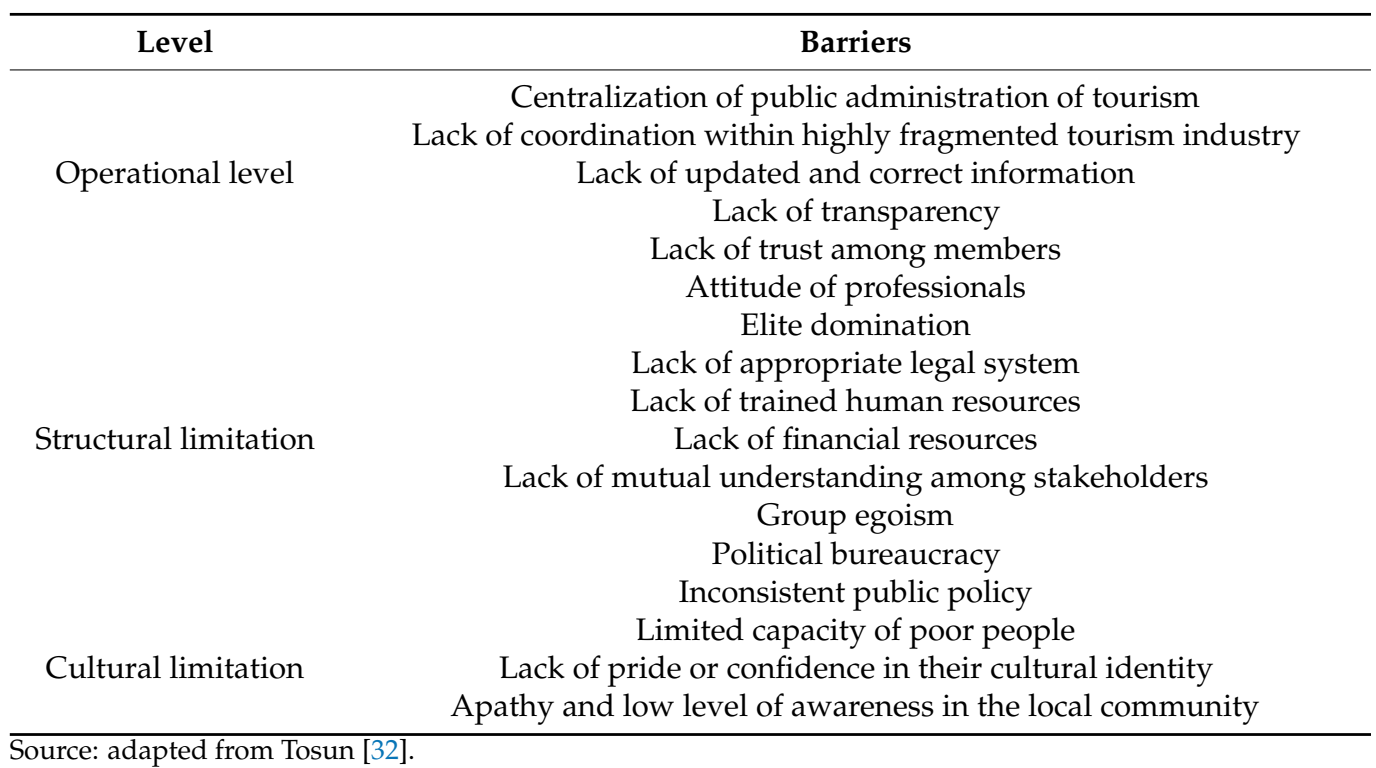

Fundamental to hindering successful community-based collaboration are three variables: power relations, resident unawareness, and the capacity and conflict nature of collaboration [37]. Power relations are an integral element in comprehending the characteristics and triggers of community-based collaboration [14,29]. Power is always a special kind of social relation that only exists through people's actions, signifying that power is not managed easily [21]. Those who hold power may resist its redistribution, thereby hindering attempts at collaboration. Agencies such as municipal governments are not excluded from this kind of power relationship. Political theorists have demonstrated that governance institutions have their own agendas in the formulation and implementation of policy [8].

In addition, unbalanced power structures can be found among the local elite and resident representatives who acquire new power [35]. It naturally follows that communities need to possess power and resources. However, grass-root levels have limited capacity (time, money, and skills, etc.) to handle matters which directly affect their dignity. This is more serious in developing countries [38]. It is normally accepted that there is a low level of awareness about, and interest in, socio-cultural, economic, and political issues among the public [32]. There is also a lack of appreciation that tourism is an industry that can influence community power over the environment [39]. Citizens tend to participate only when strongly motivated to do so.

\section{Methodology}

\subsection{Jeju Island and Its Cultural Characteristics}

Jeju Island is located southwest of the Korean peninsula. It is the biggest island and smallest province in South Korea. It is $73 \mathrm{~km}$ from east to west, $41 \mathrm{~km}$ from north to south, and oval-shaped. The island has an area of $1845 \mathrm{~km}^{2}$ and a population of about 674,000 in 2021. Mt. Hallasan, formed by a volcanic event over 1.8 million years ago, is the highest mountain in the country and rises to $1950 \mathrm{~m}$ above sea level. The rest of the island is covered with dark grey volcanic rocks and volcanic ash soil. Relatively isolated from the rest of the world, the island's natural environment has been well preserved. As such, the island is a valuable asset for research on geological features and the topography of volcanic landforms such as volcanic cones and lava tubes. Jeju's lava tubes are some of the most beautiful in the world, featuring dark walls and various colors of carbonization on the ceilings and ground.

Among the many natural formations, Mt. Hallasan National Park, Seongsan Tuff Cone, and the Geomunoreum Volcanic Cone lava tube system have jointly been designated as a 
World Natural Heritage Site by UNESCO. There are around 40 parasitic volcanoes in the surrounding area. A variety of animals and plants inhabit the slopes, including the largest forest of Korean fir trees in the world. In addition, the top of Hallasan Mountain offers a view of the magnificent vista over the entire island. The peak also holds a crater lake that is both beautiful and highly valued in academic research. Jeju Island has been a typical tourist destination for decades in South Korea as a destination for honeymooners, leisure, sports, MICE, eco-tourism, and education tourism. In total 15,286,136 tourists visited the island in $2019,13,560,004$ domestic $(88.7 \%)$ and $1,726,132$ overseas $(11.3 \%)$ tourists. Several places in Jeju Island were listed as World Heritage Sites in 2007, including the volcanoes and caves [40]. Table 2 presents the tourist arrival numbers to Jeju Island in recent years.

Table 2. Tourist arrival numbers of Jeju Island.

\begin{tabular}{cccc}
\hline & Domestic & Foreign & Total \\
2001 & $3,907,524$ & 290,050 & $4,197,574$ \\
2002 & $4,226,019$ & 289,496 & $4,515,515$ \\
2003 & $4,692,373$ & 221,017 & $4,913,390$ \\
2004 & $4,603,297$ & 329,215 & $4,932,512$ \\
2005 & $4,641,552$ & 378,723 & $5,020,275$ \\
2006 & $4,852,638$ & 460,360 & $5,312,998$ \\
2007 & $4,887,949$ & 541,274 & $5,429,223$ \\
2008 & $5,281,501$ & 540,516 & $5,822,017$ \\
2009 & $6,523,938$ & 623,354 & $7,147,292$ \\
2010 & $7,578,301$ & 777,000 & $8,355,301$ \\
2011 & $7,695,339$ & $1,045,637$ & $8,740,976$ \\
2012 & $8,010,304$ & $1,681,399$ & $9,691,703$ \\
2013 & $8,517,417$ & $2,333,848$ & $10,581,265$ \\
2014 & $8,945,601$ & $3,328,316$ & $12,273,917$ \\
2015 & $11,040,135$ & $2,624,260$ & $13,664,395$ \\
2016 & $12,249,959$ & $3,603,021$ & $15,852,980$ \\
2017 & $13,522,632$ & $1,230,604$ & $14,753,236$ \\
2018 & $13,089,129$ & $1,224,842$ & $14,313,961$ \\
2019 & $13,560,004$ & $1,726,132$ & $15,286,136$ \\
\hline
\end{tabular}

Source: Jeju Provincial Government [40] (units: a person).

As it is off the Korean Peninsula, it has maintained its interesting and distinctive culture and livelihood heritage for centuries. The local culture of Jeju Island includes historical relics, native industry, and folklore. The culture has been shaped by the island's long and often bitter struggle against foreign invaders. There are three things abundant in Jeju, (called 'Samda' in Korean), Seokda (abundant in rocks), Pungda (abundant in wind), and Yeoda (abundant in women). Seokda originated from Mt. Halla's past volcanic activity. People cultivated the land through a long process of clearing away the numerous rocks, forming inlets for irrigation and constructing walls for protection against the wind. Jeju is in the path of typhoons; hence, the islanders must fight the air and sea. Pungda and Seokda imply the harsh life of Jeju people. Yeoda originated from the fact that most Jeju men were lost at sea, resulting in a larger number of women. Women also had to work in the fields alongside men due to the harsh environment. Yeoda is a metaphor for women in Jeju working diligently. The famous women-divers who fight against wild waves to catch fish are a proud cultural symbol of Jeju Island.

'Sammu' literally means 'three non-existing things' and is a term meaning there are no thieves, gates, and beggars in Jeju. From the old days, Jeju Islanders have made 'diligence, thrift, interdependence' their virtues. Therefore, they did not steal or beg, leading to no need for gates. They all highly valued their honor and dignity, they knew everything about each other, and this prohibited them from doing anything dishonorable. Jeju has very special folklore quite different from that of mainland Korea because the food, clothing, shelter, faith, and customs are unique and peculiar to the island. In addition, being an isolated island, oral traditions such as proverbs, myths, legends, and folk songs abound. 


\subsection{Jeju Free International City Plan}

The Jeju Free International City Plan (JFICP) was developed by the Korean Government in 2001 based on the Jeju Free International City Act passed by the National Assembly in 2001. The plan allows free movement of people, goods, and capital to and from the island by easing various rules and regulations. The expansion of leisure facilities offering lodgings and the opportunity to tour the natural environment at a reasonable cost should improve tourism. The introduction of a 'Quality Assurance System' enables Jeju to attract tourism companies offering quality holiday packages [40].

The Korean Government assigned the implementation of the strategies to the National Committee of JFIC and the JFIC Development Centre. The former organization co-ordinates various public policies related to JFICP and designates investment promotion zones. The latter represents the private sector and establishes more specific strategies, and implements them while promoting and marketing to attract investment and provide a one-stop service. Jeju Island became a 'Special-Governing Province' in 2007, which permits the Provincial Government to decide on important proposals affecting it. The Provincial Government has autonomy in education, taxation, finance, and even licensing of casinos and the employment of foreign nationals. Under the system, residents are empowered to participate when mutual agreement is needed. Allowing residents to decide on important proposals affecting their lives marks a step forward in the nation's participatory democracy.

However, the extent to which this initiative will remain as a component of local development processes remains to be seen. The Jeju Civil Society Organization, consisting of 900 volunteers, all residents of Jeju, was established in 1991. The organization aims to conserve nature and improve residents' lives as well as protect social justice and democracy. Their activities include raising public awareness in support of conserving nature, providing an annual analysis of the local government budget, and encouraging the concept of ecotourism. Their activities have included an anti-cable car campaign for Mt. Halla, designing Mt. Halla's eco-tourism program, and planning a civil rights center [40]. Stakeholders in the Jeju Free International City Proposal (JFICP) Policies (local government, Jeju Free International City Development Centre, tourism industry, Local press, NGOs, and academics) also presented different views and interests on several issues, which caused conflict rather than consensus [40]. In terms of collaboration as a mechanism for cultural sustainability, the possibility that residents are influenced by personal benefits [14] and fail to consider community development benefits weakens the rationale for community-based tourism collaboration [12].

\subsection{Data Collection}

A variety of secondary data for this study were collected through local newspapers and from government documents related to current and future tourism development in the island. These data were used to comprehend tourism and environmental transitions from political, economic, and socio-cultural aspects on Jeju Island. Based on the secondary data, having completed the interview design, the pilot study was conducted among five residents of the island who were acquaintances of the researcher in August 2019. After the pilot study, some modifications were undertaken to increase clarity throughout the interview sheet.

Primary data were collected by way of interviews with 20 residents for 3 weeks in September 2019. The interviewees were approached and selected by the snowball sampling method while the researchers made great efforts to have them from various sociodemographic features (age, place of residence, gender, occupation, etc.). Consequently, valuable, various, and diverse range of information was gathered from different groups of people without the constraint of a homogeneous or biased sample. In order to collect as many objective and various opinions as possible from residents across the island, not all the interviewees were directly involved with the tourism industry. However, because the entire island has predominantly been a well-known tourist destination for the past several decades, the majority of residents were well-aware of the recent tourism development 
issues on the island. No personal information was collected as this research focuses on cultural perception and collaborative issues. All interviews were carried out at a local café near their residential place or workplace, so they could feel comfortable with the setting helping their motivated and natural response. In addition, the names of residents are excluded as protection of interviewees' anonymity is important.

The face-to-face structured and semi-structured interviews were focused on: (a) what kind of elements of cultural sustainability are constructed in Jeju Island and how they are progressed among local residents in the island? Additionally, (b) what are the key preconditions for the success of community-based tourism collaboration? The interview took from $20 \mathrm{~min}$ to $60 \mathrm{~min}$, with most of the interviews lasting around $30 \mathrm{~min}$. It was noticed that after a few questions, most of the interviewees become more comfortable and seemed enthusiastic about the topic. Most interviews were tape-recorded with their consent to ensure credibility as well as bring a more natural rapport. All the interviews were conducted in Korean and were translated to English for the final analysis. The characteristics of the 20 interviewees are described in Table 3.

Table 3. Interviewee characteristics.

\begin{tabular}{ccccc}
\hline No. & Gender & Age & Occupation & Years of Residence in Jeju \\
\hline 1 & Female & $40 \mathrm{~s}$ & Self-employed & 43 \\
2 & Male & $30 \mathrm{~s}$ & Public servant & 36 \\
3 & Female & $40 \mathrm{~s}$ & Professor & 41 \\
4 & Male & $30 \mathrm{~s}$ & School teacher & 8 \\
5 & Male & $30 \mathrm{~s}$ & Office worker & 12 \\
6 & Male & $30 \mathrm{~s}$ & Public servant & 26 \\
7 & Male & $20 \mathrm{~s}$ & Researcher & 6 \\
8 & Female & $30 \mathrm{~s}$ & Housewife & 13 \\
9 & Female & $40 \mathrm{~s}$ & Salesperson & 37 \\
10 & Male & $50 \mathrm{~s}$ & Self-employed & 40 \\
11 & Female & $20 \mathrm{~s}$ & Student & 8 \\
12 & Female & $30 \mathrm{~s}$ & Self-employed & 12 \\
13 & Male & $40 \mathrm{~s}$ & Trade & 38 \\
14 & Male & $30 \mathrm{~s}$ & businessman & 37 \\
15 & Male & $30 \mathrm{~s}$ & Historian & 33 \\
16 & Male & $40 \mathrm{~s}$ & Prfice worker & 46 \\
17 & Male & $20 \mathrm{~s}$ & Part-time & 2 \\
18 & Female & $30 \mathrm{~s}$ & worker & 6 \\
19 & Male & $30 \mathrm{~s}$ & Student & 5 \\
20 & Female & $30 \mathrm{~s}$ & Service sector & 20 \\
\hline
\end{tabular}

\section{Results and Findings}

NVivo, a qualitative analysis tool from QSR International, was utilized for analyzing the collected data in this study. NVivo's strong coding function is one of its main features, but it also has other useful functions, including Set, Query, Link, Model, and others. After the text was inputted into the NVivo software, three steps were followed: descriptive coding, interpretive coding, and overarching themes. In addition, as the interviews were recorded, the researcher could easily recall what they wanted to clarify and interpret delicate expressions from interviewees by manually tracing important parts. For this analysis, 20 people were interviewed, 12 men and 8 women. On the age of the participants, those in their 30s top the list (11 interviewees), followed by those in their 40s (5) and 20s (3). More than half of them were long-term residents who had lived in Jeju Island for 20 years or more. 


\subsection{Cultural Exchange}

A key concern that arose from the interviews was cultural exchange. One respondent stressed that tourism development was needed in Jeju for cultural exchange with people from around the world:

Jeju people are like to be very exclusive to people from other places, and they have a strong intimacy within the community. It is called a 'Gaendang' culture. For instance, Jeju Island is the only Department Store Lotte (one of the three leading department store chains in the country) that failed. As Lotte brought Seoul (the capital and largest city in South Korea) people in dealing with service, but Jeju people tend to buy things from whom they are familiar with, though the quality of the item may be lower.

(Interviewee No. 10.)

Although it will not be changed easily due to the natural disposition, we need to alter our consciousness by meeting new people. Through globalization of our mental vision, development will be achieved, and we could do other things for a living.

(Interviewee No. 3.)

One positive cultural impact of tourism is the stimulation of festivals and cultural events. Most of the interviewees perceived increased cultural and artistic activities, though one doubts that these originated from tourism development:

Tourism brought an added value in cultural aspects. For instance, residents in Seogwipo City (the second-largest city on the island) can watch a cinema in a first-run theatre without going to Jeju City (the largest city on the island) anymore, and more public performances and concerts are now held near or in the Jeju Convention Centre, so we do not have to go to the mainland.

(Interviewee No. 1.)

It has been improved, even though I doubt the benefits are from tourism. However, there is still a lack of full use of cultural space, and it tends to focus on urban areas.

(Interviewee No. 14.)

On the other hand, all interviewees did not think that current tourism planning helped the preservation of historical and cultural sites on the island:

Tourism should help, but it is insufficient.

(Interviewee No. 19.)

Tourism may not assist the preservation of those sites, while I have not yet heard that tourism damages them.

(Interviewee No. 16.)

\subsection{Cultural Identity and Values}

All the interviewees reported that they did not feel that residents altered their behavior to imitate the behavior of visitors and said that any changes would rather occur from watching cable television, internet, or peer groups:

Communication tools have been much improved in Jeju. For instance, there is such a cable channel that guides recent fashion inviting the public, or young people sometimes are influenced by their peer group about how to wear clothes.

(Interviewee No. 11.)

This indicates that mass media has been reducing cultural shock or clashes from tourism, and Jeju is no exception. In response to questions about changes due to tourism, 
their views were various, but they were similar in respect to traditional value and moral norms - these are not changing:

I do not feel any specific changes yet in our lives caused by tourism.

(Interviewee No. 13.)

I do not know, maybe it is about to change, but you know, for instance, we have the unique custom of mowing the grass around our ancestors' graves. At that time, many people who were away from their homes came back to Jeju, and all family and relatives gather together. Most companies and schools in Jeju Island even give a holiday for this traditional filial duty. These kinds of things will not be altered because of tourism.

(Interviewee No. 8.)

Maybe it depends on the kind of job we have. However, the food we eat, the way we speak (a unique and strong dialect of Jeju Island), or the religious service we perform for our ancestors will not be easily changed. I do not want it to be transformed. We appreciate our own values and lifestyle of Jeju Island.

(Interviewee No. 2.)

However, one resident criticized the excessive emphasis on English in Jeju Island:

I think it is not a real picture of a globalized citizen that people only chase English such as itself is objective, without concerning the content of a valuable community culture that native language symbolizes.

(Interviewee No. 15.)

Jeju people have had a strong family oriented culture for the last several centuries. The responses demonstrate that Jeju Islanders still respect their traditional values and moral norms, and they have strong cultural pride. In terms of the English boom on Jeju, this is interpreted as being derived from tourism and the establishment of schools for foreigners after the JFICP. This English boom could be a challenge threatening the cultural identity of the Jeju people. Some interviewees were not sure about cultural change; most cultural impacts are intangible and more easily seen over the long-term [22].

\subsection{Community Power E Control}

Most residents do not perceive economic benefits from tourism, whether they are positive toward tourism or not. One respondent who was satisfied with the JIFCP and tourism in Jeju mentioned that:

I have heard that the local economy is coming down; from JFICP, it was expected there would be a reduction of taxation, but it did not happen.

(Interviewee No. 12.)

In response to asking if tourism is more concerned about visitors than local people, most respondents argued that it is:

Under the purpose of facilitation of the number of tourists, tourism development too much relies on external capital.

(Interviewee No. 20.)

Tourism development in Jeju has had a harmful influence on the natural environment. The tourism industry creates profits, but there are many cases that the residents put up with its several negative influences. There have been large benefits from the duty-free shop in Jeju International Airport, but the benefits were not shared with the local community. Tourism industries only tend to focus on their operation. 
Local people are not keen on development behavior itself, but because of the expectation of some economic benefits from the tourism, they show quite positive support for tourism development. Actually, there are considerable harmful environmental and cultural effects, which tourism industries or local government should consider together with the pursuit of economic benefits.

(Interviewee No. 7.)

Environmental damage due to tourism is a critical issue for residents. From prehistory, their unique culture has been deeply grounded in the environment. This close relationship between the physical environment and cultural values in Jeju means any environmental disturbance by tourism is linked to cultural intrusions. Moreover, this does not just apply to residents [6]. Environmentally unsustainable tourism practices induce direct challenges to those culturally defined meanings — the sacred landscape on Jeju Island-which fulfill visitor expectations. Tosun [32] contends that externally derived tourism development threatens residents with unwanted development, causing a loss of local control over local tourism development. JFICP, designed by the Korean Government, encourages extensive foreign investments, adopting policies favorable to foreign investors. Such a top-down approach to planning poses an unavoidable danger to Jeju people. Haywood [41] writes, 'their way of life, their institutions and their culture being bought and sold, with communities being internationally planned and constructed for consumption by tourists'. One of the interviewees stated regarding this concern:

Initially, the concern of tourists would be pervasive, but the situation will not happen like that. For instance, when the E-mart (a mega-size retail outlet chain) was first launched in Jeju Island, all created earnings were sent to the bank in Seoul. However, later, the E-mart used the Jeju bank since Jeju people were becoming hostile to this shopping mall.

(Interviewee No. 18.)

Residents in Jeju can hold indirect control by using actions such as boycotts. However, such control seems to be dominated by powerful capital-driven enterprises. For instance, E-mart might have considered the residents to attract them again to their business, not to practice ST principles. Likewise, tourism businesses that build mega-leisure facilities target national and international tourists rather than local people, and do not try to hear local voices for instrumental reasons. It is difficult to reflect local views and maintain real control over Jeju Island. The signs of loss of local control and its negative influence on community culture are revealed by some interviewees:

I feel that it is hard to make sense of unity in my town 'Gumack'. There is no interaction with people on the golf course as well as the Catholic group, who is a kind of independent society. Since the development of the golf course in town, they have yet recruited local people or have supported the community.

(Interviewee No. 4.)

There have been several changes; tourism industries tend to just use community and so affect the local traditional businesses in a bad way. Even though there are good principles of 'Special Municipality', these are just written in a document. To be activated, it should coexist with the community culture.

(Interviewee No. 17.)

Despite Jeju people having pride in their culture, as discussed earlier, it is not strong enough to preserve cultural identity, as they are fragile in front of certain cultural intrusions. Failures in cultural integration or cultural belonging, threats to the existence or viability of unique businesses in Jeju Island result from current tourism practices, regardless of whether tourism entrepreneurs and authorities intend these outcomes. Wearing and McDonald [21] interpret this phenomenon as the self/other dichotomy, where the 'self' of tourism is prioritized over the 'other' of the isolated community. In addition, cultural 
benefits, such as cultural activities or cultural exchange, might not really contribute to cultural sustainability. These benefits have temporary effects and lead to cultural tension or exploitation rather than to enhanced cultural values. Mowforth and Munt [22], p. 99, define cultural sustainability as 'the ability of people to retain or adapt elements of their culture which distinguish them from other people'. By this definition, there are negative indications of cultural sustainability on Jeju Island. Cultural identity, cultural subjectivity, and cultural rights are considered the root of cultural sustainability, and these key elements are associated with community-based tourism collaboration since they offer opportunities for formal control (power), enabling communities to reject or accept tourism demands.

\subsection{Triggers of Community-Based Tourism Collaboration}

There are unique factors in understanding tourism development and sustainability in newly industrialized countries such as Korea. Compared to their relatively well-established economic situations, their political and systematic infrastructure is not developed [34]. Changes have been observed in the political structure since Jeju was designated a 'Special Municipality', independent from central government control except for national defense and diplomacy. These changes give more opportunities to local people to participate in their community. Several NGOs and local community groups have made significant efforts to achieve community participation. Notwithstanding these positive moves, this research found several barriers to sustainability through community-based collaboration, specifically in the tourism industry. Currently, there is no institution for community-based tourism collaboration; one of the interviewees belongs to a citizen group. In relation to the willingness to participate in tourism planning and development, more than half of the interviewees did not want to be involved. Frequently mentioned reasons were:

Well, if people are related to tourism for a living ... yes, but do people need to engage in the collaboration if it is not the case?

(Interviewee No. 11.)

I would feel that my time is interrupted unless there are visible benefits for me.

(Interviewee No. 9.)

We could live with our land, house, hereditary property, even orange production.

(Interviewee No. 6.)

The responses above indicate that one barrier to successful collaboration is the residents' reluctance to be involved in tourism. Some residents do not appreciate that tourism is an industry that can influence environments, and attitudes are largely influenced by personal benefits. People who do not directly benefit from tourism will not be interested in collaborating with it. When asked about expected barriers to successful community-based collaboration, this lack of willingness to participate was confirmed:

Lack of willingness to participate will be the most difficult obstacle for collaboration. We do not know much about tourism and the sort of collaboration issues. Many local people still do not work if it is rainy. We value our way of life and traditional culture. It is not easy to alter people's dispositions. We have lived in a slow wave of society for a long time.

(Interviewee No. 17.)

The barriers are related to limited capacity and a kind of exclusivist attitude toward the 'new', shaped by the island's long struggle against foreign invaders. Ironically, this strong attachment to their culture is negatively linked to attitudes about 'new'; community participation can be effective in cultural sustainability. Resistance is human nature; they feel insecure or afraid of change; they do not like the uncertainty associated with change; they do not understand the consequences of change [18]. Most of the interviewees who wanted to be involved in tourism collaboration expressed worries about socio-cultural impacts. They seemed to have a more realistic understanding of tourism impacts and emphasized the absence of legitimized institutions to support their participation: 
We need a legalized body that enables us to hear and integrate the opinions of the residents.

(Interviewee No. 3.)

Lack of institutionalized provision is the most serious problem. Sometimes there is a company presentation for residents about the environmental impacts of tourism resort planning. Thus, local people could evaluate it, and occasionally a part of our opinions is accepted, adjustment of the tourism planning occurs. However, these processes always take place after all the tourism planning was completed; hence, it is not possible to cancel, though the planning is not appropriate environmentally or socially.

(Interviewee No. 16.)

Administrative support to legitimate stakeholders to encourage collaboration is necessary. Sofield [42] stresses that legitimating residents through government support is a prerequisite for effective community-based tourism. Some scholars emphasize the importance of local community involvement through certain programs (festivals or events). However, this must be extended politically to capture a full sense of community empowerment. Locals joining tourism planning could further enhance self-esteem due to outside recognition of the uniqueness and values of their community culture [34]. The lack of institutionalized provision by the government on Jeju Island brought none of these benefits. Jeju people seem to be skeptical toward community-based collaboration. All the interviewees, regardless of their willingness to participate, stated that it is complicated with respect to power dominance as well as local people's resistance:

Yes, it will be achievable, but it will take about 20 years; it is not a sort of easy work.

(Interviewee No. 10.)

Local people are subject to large capital flows in relation to enterprises. The residents do not want to sell their land to external businesspeople. However, the situation is not that. The disparities of resources are too huge. In this circumstance, how can effective collaboration for the community be achievable?

(Interviewee No. 8.)

Power relations are fundamental to comprehending the triggers of community-based collaboration [14,42]. On Jeju Island, under JFICP, large capital flows aimed at tourism development on a mass scale were initiated.

\subsection{Relationship between Cultural Sustainability and Community-Based Collaboration}

In environmentally and culturally sensitive destinations, collaboration should offer flexibility that will incorporate the results of cumulative studies with changes in socio-political conditions. Hence, active participation by key stakeholders is essentialspecifically in those communities that are experiencing strong growth and change due to tourism [14] as on Jeju Island:

I would like to give my efforts to reflect the actual issues of the community through tourism collaboration.

(Interviewee No. 9.)

I want to enhance and develop the quality of our lives by applying endemic cultural contents to tourism development.

(Interviewee No. 4.)

However, the collaboration itself does not ensure sustainability:

The fact that the Special Municipality has appeared in Jeju Island is not well enough to say local people have much better opportunities, including in the 
political light. It should settle down well to avoid a side effect such as the municipal governor overusing the power.

(Interviewee No. 1.)

Therefore, it is unnecessary for municipal governments to be neutral conveners of power in initiating and facilitating successful tourism collaboration [14].

\section{Conclusions}

\subsection{Discussion}

Residents of Jeju Island perceive that they receive cultural benefits from tourism in terms of increased cultural and artistic activities. Some appreciate the value of cultural exchange. Jeju people hold a strong attachment to their unique culture. The JFICP, designed by the Korean Central Government, encouraged externally derived tourism and negatively influences local people in terms of economic and environmental benefits, traditional businesses, and cultural integration. Under unsustainable tourism practices, residents are not effectively involved in reflecting local views and maintaining real control over the destination. Residents became fragile when facing cultural intrusions. At the same time, enhanced cultural exchange gained from tourism does not contribute to cultural sustainability. These kinds of benefits have temporary effects and lead to cultural tension or exploitation. There are definite indications of negative cultural sustainability on Jeju Island. Cultural identity, cultural subjectivity, and cultural rights are considered the root of cultural sustainability on Jeju.

The key cultural element associated with successful community-based tourism collaboration is to offer opportunities for formal control (power), which enables communities to reject or accept tourism demands. This research found that several barriers exist to sustainability through community-based tourism collaboration on Jeju: the locals' lack of willingness to participate, absence of institutionalized provision, and power disparities. Locals' strong attachment to their culture is linked to negative attitudes to new things (community participation). In addition, the absence of legal provisions for community participation prevents people willing to participate from doing so or leads to token participation. Power disparities are fundamental to hindering community-based tourism collaboration. Under the JFICP, large capital flows leading to tourism development on a mass scale make the community vulnerable. The central government, encouraging this power dominance by activating JFICP, indicates that the intrinsic right of Jeju people to self-determination cannot be achieved automatically or by other people such as government authorities.

Community-based collaboration on Jeju Island is essential, since changes will significantly affect the dignity of local people. All interviewees willing to engage in tourism collaboration presented strong concerns about the quality of life and endemic culture. The findings support the strong relationship between community-based collaboration and cultural sustainability since community participation is an instrument for sustainability. However, collaboration itself does not result in a sustainable community or cultural rights while current power disparities exist. Hence, in addition to expecting sustainable tourism policy and management, residents should acquire power by themselves. Power relations that favor tourism will gain ascendancy as the nature and structure of the community itself change through alterations to attitudes, education, and economics. Then, a communitybased collaboration will be initiated that suits the cultural needs of Jeju residents.

This study investigates and applies stakeholder theory particularly focused on cultural sustainability for local residents and other grass-root stakeholders as a case of the megatourism development projects initiated by the central government. It emphasizes the intangible significance and shared value maintained and cherished by local stakeholders as a result of the tourism development that cannot be numerically simplified and replaced by tangible benefits commonly led by the central government. As a case report, this study delivers an insightful lesson that deepens the value of precedent studies for the stakeholders and cultural sustainability that can be adopted by many other regions or countries. 


\subsection{Managerial Implications and Recommendations}

In practical terms, there are points regarding the importance of the community that policymakers and tourism industries should take into account: (a) visitor motivations are changing; they are more in line with the characteristic of sustainable tourism seeking a fruitful and authentic engagement with reality through human interaction; (b) Jeju has a great natural environment as a UNESCO World Natural Heritage Site and unique island culture, which large cities cannot imitate, and (c) tourism can gain viability through differentiation from other destinations. In addition, Jeju Island targets international tourists who value unique and distinctive cultural exchange. Hence, Jeju tourism will not be externally driven tourism and will necessarily follow the host destination pursuing cultural and environmental integrity.

From the findings of the secondary data and conducted in-depth interviews, the current study presents insightful messages to the practitioners in the tourism industry. First, the 'authentic modern' denotes that modernity is not constructed separately but, in a process, oriented approach, one in which human subjectivity is engaged in the process of socio-cultural and economic change [34]. Residents need to alter their closed attitude toward new things and try to seek the 'authentic modern'. Local NGOs and community groups should conduct citizen education on tourism impacts and how to enhance community participation, and pressure businesses and the municipality.

Second, participation in small-scale development should develop into community involvement in overall tourism planning. Such a process will help the community and individuals to be more empowered as well as prove locals' increased capacity to others. The route could be leading a small event or festival, and then developing an indicator program that enables the monitoring of sustainability. The indicators designed by locals also lead communities toward more sustainable positions through the sensitivity of the community to development. Residents need to proactively participate in local issues the Special Municipality is carrying out through elections or Internet communication.

Third, local mess media, as an objective third party and objective agency, should give more attention to the less powerful stakeholders, the residents. In the same sense, sustainable tourism policy and tourism practices should pay attention to the local community, the cultural dimension, which can be easily neglected. A scenario of tourism based on the deconstruction of the self/other dichotomy may see the self-worth and dignity of local people incorporated into tourism.

\subsection{Limitations and Further Research}

This study could not make a complete evaluation of tourism-related cultural issues in Jeju through interviews because culture and cultural change is intangible and normally exhibited over the long-term. Jeju Island is in a political, economic, and environmental transition period, and cultural impacts will be revealed following these changes. Thus, culture was hard to measure, and the authors estimated it mainly from residents' views and whether they were involved in tourism or not. In addition, it is not possible to come up with an explanation that will predict local outcomes with any certainty. Residents are heterogeneous in characteristics, including personal benefit, eco-centric value, education level, and age, etc. Hence, the diversity of conditions at the local level limits the validity of the research. More interviews with policymakers and other business stakeholders to assess collaboration barriers in depth would be useful.

Thus, a cumulative study is necessary to monitor how future tourism development influences local people on Jeju and its cultural sustainability. Even though the authors used cultural indicators (such as cultural exchange value, increased cultural and artistic activities, attachment level to culture, cultural belonging, cultural integration, satisfaction level to tourism, and whether residents were involved in tourism or not), these might not be sufficiently verified to fully assess cultural sustainability and further that in a specific destination such as Jeju Island. Therefore, future studies should use cultural indicators, or general indicators, that are applicable to Jeju Island or elsewhere in Korea or beyond. 
Author Contributions: Conceptualization, X.L.; methodology, J.S.K.; validation, T.J.L.; formal analysis, X.L.; resources, X.L.; data curation, J.S.K.; writing—original draft preparation, X.L.; writingreview and editing, T.J.L.; supervision, T.J.L.; project administration, J.S.K.; funding acquisition, X.L. and J.S.K. All authors have read and agreed to the published version of the manuscript.

Funding: This paper was supported by the Guangxi Philosophy and Social Science Planning Office (Grant number: 18BMZ007) in China. This paper was supported by the Sehan University Research Fund in 2021 (Grant number: sh2093) in Korea.

Institutional Review Board Statement: The study was conducted according to the guidelines of the Declaration of Helsinki and approved by the Institutional Review Board of the Guangxi Normal University (25 April 2021).

Informed Consent Statement: Informed consent was obtained from all subjects involved in the study.

Data Availability Statement: Data sharing is not applicable.

Conflicts of Interest: The authors declare no conflict of interest. The funders had no role in the design of the study; in the collection, analyses, or interpretation of data; in the writing of the manuscript, or in the decision to publish the results.

\section{References}

1. Fong, S.-F.; Lo, M.-C.; Songan, P.; Nair, V. Self-efficacy and sustainable rural tourism development: Local communities' perspectives from Kuching, Sarawak. Asia Pac. J. Tour. Res. 2017, 22, 147-159. [CrossRef]

2. Suntikul, W. Cultural sustainability and fluidity in bhutan's traditional festivals. J. Sustain. Tour. 2018, 26, 2102-2116. [CrossRef]

3. Kim, J.S.; Lee, T.J.; Hyun, S.S. Estimating the economic value of urban forest parks: Focusing on restorative experiences and environmental concerns. J. Destin. Mark. Manag. 2021, 20. [CrossRef]

4. Okonkwo, E.E.; Odey, A.O. Impact of sustainability on tourism development in nigeria: A case study of cross river state, nigeria. Int. J. Tour. Sci. 2018, 18, 89-109. [CrossRef]

5. Murphy, P.E.; Price, G.G. Tourism and sustainable development. In Global Tourism, 3rd ed.; Theobald, W.F., Ed.; Elsevier: Amsterdam, The Netherlands, 2005; pp. 194-212.

6. Eslami, S.; Khalifah, Z.; Mardani, A.; Streimikiene, D.; Han, H. Community attachment, tourism impacts, quality of life and residents' support for sustainable tourism development. J. Travel Tour. Mark. 2019, 36, 1061-1079. [CrossRef]

7. Graci, S.; Dodds, R. Sustainable Tourism in Island Destinations; Earthscan: London, UK, 2010.

8. Adongo, R.; Choe, J.Y.; Han, H. Tourism in Hoi An, Vietnam: Impacts, perceived benefits, community attachment and support for tourism development. Int. J. Tour. Sci. 2017, 17, 86-106. [CrossRef]

9. Twining-Ward, L.; Butler, R. Implementing STD on a small island: Development and use of sustainable tourism development indicators in samoa. J. Sustain. Tour. 2002, 10, 363-387. [CrossRef]

10. Clarke, J.A. Framework of approaches to sustainable tourism. J. Sustain. Tour. 1997, 5, 224-233. [CrossRef]

11. Duval, D.T. Tourism in the Caribbean: Development, Management, Prospects; Routledge: London, UK, 2004.

12. Holtorf, C. Embracing change: How cultural resilience is increased through cultural heritage. World Archaeol. 2018, 50, 639-650. [CrossRef]

13. Walker, T.B.; Lee, T.J.; Li, X. Sustainable development for small island tourism: Developing slow tourism in the caribbean. J. Travel Tour. Mark. 2021, 38, 1-15. [CrossRef]

14. Lee, T.J.; Riley, M.; Hampton, M.P. Conflict and progress: Tourism development in Korea. Ann. Tour. Res. 2010, 37, 355-376. [CrossRef]

15. Boussaa, D. The past as a catalyst for cultural sustainability in historic cities: The case of doha, qatar. Int. J. Herit. Stud. 2021, 27, 470-486. [CrossRef]

16. Kang, E.J.; Scott, N.; Lee, T.J.; Ballantyne, R. Benefits of visiting a 'dark tourism' site: The case of the jeju april 3rd peace park, Korea. Tour. Manag. 2012, 33, 257-265. [CrossRef]

17. Zhang, Y.; Xiong, Y.; Lee, T.J.; Ye, M.; Nunkoo, R. Socio-cultural sustainability and the formation of social capital from communitybased Tourism. J. Travel Res. 2021, 60, 656-669. [CrossRef]

18. Cole, S. Cultural tourism, community participation and empowerment. In Cultural Tourism in a Changing World: Politics, Participation and (Re)presentation; Smith, M.K., Robinson, M., Eds.; Channel View: Clevedon, UK, 2006; pp. 89-103.

19. Hudson, S.; Miller, G. Ethical considerations in sustainable tourism. In Global Tourism, 3rd ed.; Theobald, W., Ed.; Elsevier Publishing: Amsterdam, The Netherlands, 2005; pp. 248-266.

20. Depperu, D.; Magnani, G.; Crosato, L.; Liberati, C. Growth of firms in a fragmented cultural industry: Italian commercial art galleries' competitive strategies. Sustainability 2021, 13, 5057. [CrossRef]

21. Wearing, S.; McDonald, M. The development of community-based tourism: Re-thinking the relationship between tour operators and development agents as intermediaries in rural and isolated area communities. J. Sustain. Tour. 2002, 10, 191-204. [CrossRef] 
22. Mowforth, M.; Munt, I. Tourism and Sustainability: Development and New Tourism in the Third World, 2nd ed.; Routledge: London, UK, 2003.

23. Robinson, M.; Boniface, P. Tourism and Cultural Conflicts; CABI: New York, NY, USA, 1999.

24. Zhang, Y.; Lee, T.J.; Xiong, Y. A conflict resolution model for sustainable heritage tourism. Int. J. Tour. Res. $2019,21,478-492$. [CrossRef]

25. Lee, T.J. Role of hotel design in enhancing destination branding. Ann. Tour. Res. 2011, 38, 708-711. [CrossRef]

26. Aas, C.; Ladkin, A.; Fletcher, J. Stakeholder Collaboration and heritage management. Ann. Tour. Res. 2005, 32, 28-48. [CrossRef]

27. Throsby, D. Culturally Sustainable development: Theoretical concept or practical policy instrument? Int. J. Cult. Policy 2017, 23, 133-147. [CrossRef]

28. Ladkin, A.; Bertramini, A.M. Collaborative tourism planning: A case study of cusco, Peru. Curr. Issues Tour. 2002, 5, 71-93. [CrossRef]

29. Dredge, D. Networks, conflict and collaborative communities. J. Sustain. Tour. 2006, 14, 562-581. [CrossRef]

30. Hidalgo-Giralt, C.; Palacios-García, A.; Barrado-Timón, D.; Rodríguez-Esteban, J.A. Urban industrial tourism: Cultural sustainability as a tool for confronting overtourism: Cases of madrid, brussels, and copenhagen. Sustainability 2021, $13,4694$. [CrossRef]

31. Bramwell, B.; Lane, B. Tourism Collaboration and Partnership: Politics, Practice and Sustainability; Channel View: Clevedon, UK, 2000.

32. Tosun, C. Limits to community participation in the tourism development process in developing countries. Tour. Manag. 2000, 21, 613-633. [CrossRef]

33. Low, N. Planning, Politics and State: Political Foundation of Planning Thoughts; Unwin Hyman: London, UK, 1991.

34. Li, Y. Exploring community tourism in China: The case of nanshan cultural tourism zone. J. Sustain. Tour. 2004, 12, 175-193. [CrossRef]

35. Miller, G.; Twinning-Ward, L. Monitoring for a Sustainable Tourism Transition: The Challenge of Developing and Using Indicators; CAB International: Oxon, UK, 2005.

36. Farrell, B.; Twining-Ward, L. Seven steps towards sustainability: Tourism in the context of new knowledge. J. Sustain. Tour. 2005, 13, 109-122. [CrossRef]

37. Walker, T.B.; Lee, T.J. Contributions to sustainable tourism in small islands: Analysis of the cittaslow movement. Tour. Geogr. 2021, 23, 415-435. [CrossRef]

38. Altaba, P.; García-Esparza, J.A. A practical vision of heritage tourism in low-population-density areas. The spanish mediterranean as a case study. Sustainability 2021, 13, 5144. [CrossRef]

39. Yan, W.-J.; Chiou, S.-C. The safeguarding of intangible cultural heritage from the perspective of civic participation: The informal education of chinese embroidery handicrafts. Sustainability 2021, 13, 4958. [CrossRef]

40. Jeju Provincial Government. Statistics of Jeju Province in 2020; Jeju Provincial Government: Jeju-si, Korea, 2021.

41. Haywood, M. Responsible and responsive tourism planning in the community. Tour. Manag. 1988, 9, 105-118. [CrossRef]

42. Sofield, T.H.B. Empowerment for Sustainable Tourism Development; Emerald Group Publishing: Bingley, UK, 2003. 